\title{
Las reformas a la inmigración y su impacto en la frontera México-Estados Unidos
}

\author{
Raúl Fernández \\ Universidad de California en Irvine
}

\section{Resumen}

El presente trabajo es una reflexión sobre el impacto que las reformas de las leyes de inmigración han ejercido sobre la economía de la frontera de México en los últimos 20 años. El rápido crecimiento de esta economía, desde el cierre del Programa de Braceros a principios de los sesentas, ha sido guiado por fuerzas externas provenientes de Estados Unidos. Por su parte, en un principio el gobierno de los Estados Unidos prestó poca atención al cumplimiento de las leyes de migración establecidas ante la migración masiva de trabajadores mexicanos indocumentados hacia el sur de California. Este artículo desglosa algunos argumentos que explican los cambios que ha sufrido la migración en cuanto a los grupos étnicos que la conforman, los lugares con mayor oferta de trabajo y las propuestas de reforma a la inmigración como resultado del creciente flujo migratorio.

Palabras clave: propuesta migratoria, mano de obra, Programa de Trabajadores Huéspedes, braceros, Programa Industrial Fronterizo.

\begin{abstract}
This is a reflection on the impact that immigration laws have had over the border economics of Mexico during the last 20 years. Since the closing of the "Bracero" program in the early 60 's, the fast growth of this economics has been lead by external powers coming from the United States. For its part, at first the government of the United States paid little attention to the compliance of the migration laws in force in front of massive migration of undocumented Mexican workers to manufacturing centers of the improving economy of the South of California. This article breaks down some arguments that explain the changes that migration suffered related to ethnical groups included on it, the places that present higher job offers as well as the reformation proposals for immigration resulting from the growing migratory flow.

Keywords: migratory proposal, manpower, Guest Workers Program, "Braceros", Border Industrial Program.
\end{abstract}




\title{
LAS REFORMAS A LA INMIGRACION Y SU IMPACTO EN LA FRONTERA MEXICO-EUA*
}

\author{
Por \\ Raúl Fernández \\ Programa en Cul tura Comparativa \\ Escuela de Ciencias Sociales \\ Universidad de California en Irvine.
}

Durante más de cien años, las altas y bajas del desarrollo económico en el suroeste de los Estados Unidos han significado ciclos de atracción y repulsión de trabajadores extranjeros. Cuando el repentino auge económico produjo relativa escasez de mano de obra, los trabajadores extranjeros fueron activamente reclutados. A la inversa, los tiempos de crisis económica llevaron a prohibir el uso de mano de obra extranjera y a realizar persecucicnes y deportaciones masivas. Entre 1871 y 1875 miles de chinos entraron a los Estados Unidos y vinieron a llenar un hueco en lo referente a mano de obra para la construcción ferroviaria y para los nacientes campos agrícolas de California. Después de la crisis económica de finales de la década de 1870, el Acta de Exclusión de Chinos, de 1882, prohibió la inmigración de trabajadores de esa nacionalidad. Posteriormente, a finales de la década de 1880 , los trabajadores migrantes japoneses remplazaron a los chinos en Hawai y California, sólo para ser excluidos por el "Acuerdo de Caballeros" de Teddy Roosevelt en 1907.

Entre 1910 y 1930 , cientos de miles de trabajadores mexicanos entraron a los Estados Unidos a pizcar algodón y construir más vías ferroviarias. El primer ciclo de migración terminó con la gran depresión y la deportación de muchos trabajadores indocumentados en los años treintas 1. Durante la Segunda Guerra Mundial miles de trabajadores mexicanos (braceros) viajaron a los Estados Unidos bajo un acuerdo bilateral entre este país y México, acuerdo por el cual se permitió la contratación de trabajadores mexicanos por patrones de Estados Unidos. En 1954 la "Operación Espalda Mojada" fue lanzada para controlar el aumento en el flujo de trabajadores mexicanos indocumentados. El Programa de Braceros benefició ampliamente a buena parte de los agricultores a lo largo del Suroeste, ya que mantuvo a los braceros como poco menos que esclavos 2 . La ley que creó este programa fue revocada en 1964. Después, a finales de los años sesenta y principios de los setenta, se presentó una gran ola de trabajadores indocumentados, principalmente provenientes de México, pero también de Centroamérica y el Caribe.

\footnotetext{
*Traducción al español de Leticia Gómez Castellanos y Luz Ma. Ortega Villa

1 Ver, entre otros, Carey McWilliams, Factories in the field, Santa Barbara, 1971.

${ }^{2}$ Rosalindo M. González, Capital accumulation and Mexican inmigration to the United States. (Tesis para obtener el grado de Ph. D., sin publicar). Irvine, California, 1981.
} 
Los informes sobre la migración de extranjeros al suroeste de Estados Unidos, mostraron que el modelo de atracción-repulsión difiere de la acostumbrada noción sociológica de "estira y afloja" en dos sentidos importantes. Primero, los flujos de migración no pueden ser explicados simplemente por diferencias relativas de salario, ya que los flujos son de naturaleza cíclica más que temporal. Así, las altas y bajas de la migración extranjera corresponden a los ciclos del capitalismo y no a un proceso constante dirigido hacia el equilibrio de salarios. En segundo lugar, las fuerzas claves extraeconómicas juegan un papel importante en la regulación de los flujos. Asociaciones de patrones, granjeros, uniones de trabajadores de E.U.A. y el mismo Gobierno federal de ese país participan en el proceso. El Gobierno federal a través de varias leyes, y por la manera en que éste las ha seleccionado para ponerlas en vigor, se ha convertido en el principal elemento para la interpretación de la migración mexicana hacia el Suroeste.

A finales de los setentas, el Gobierno federal entró en una nueva etapa de rechazo de los trabajadores extranjeros. La legilación para tal efecto ha sido promovida por las administraciones de Carter y Reagan. La actual legislación sobre inmigración, que ha estado bajo debate durante los últimos cinco años, significa el comienzo de un período de control gubernamental. Esto representa la expansión hacia los Estados Unidos de un proceso que ha afectado la economía internacional desde que en 1981 el mundo se sumergió en la peor crisis global en cincuenta años. Los trabajadores extranjeros han sido expulsados de varios países a medida que sus respectivos gobiernos luchan por estabilizar sus economías, reducir el nivel de desempleo y, a la vez, culpar de los males de la economía capitalista a los extraños entrometidos ${ }^{3}$.

La legislación Simpson-Mazzoli, llamada así por los dos congresistas que la promovieron, difiere de las anteriores ya que preve a la vez la atracción de trabajadores extranjeros (la sección de "trabajadores huéspedes") y el rechazo y repatriación (la sección de "amnistía"), La diferencia resulta de los esfuerzos de los legisladores de Estados Unidos por representar cambios en los intereses económicos y en las relaciones entre Estados Unidos y México.

La cercanía de la aprobación de la ley Simpson-Mazzoli en el Congreso y la variedad de previsiones sugeridas revelan cómo la legislación sobre la inmigración se ha convertido en un área de traslape entre las políticas interna y externa del vecino país del Norte. Por su proximidad geográfica y los crecientes lazos estructurales, la relación México-Estados Unidos ha sido llevada cada vez más hacia el terreno de las discusiones sobre política interna.

\footnotetext{
Nigeria, Suiza y Alcmania, cntre otras naciones, experimentaton durante 1982 y 1983 , movimientos para repatriar trabajadores "huéspedes" extranjeros indeseables.
} 
Mientras la legislación sobre inmigración es discutida en los Estados Unidos primeramente como un problema de carácter doméstico, constituye en realidad parte integral de la política externa con México debido al tremendo impacto que podría tener en la economía interna de esta nación. Dada la situación de América Central, el gobierno de los Estados Unidos se ha preocupado con los cambios en las condiciones sociales y económicas en México, por razones de seguridad nacional: la marina de Estados Unidos obtiene gran cantidad de petróleo de México, país que es el principal proveedor extranjero de petróleo para E.U.A., el $50 \%$ o de las exportaciones de petróleo de México (aproximadamente 822,000 barriles diarios) van al mercado estadounidense. Asi, los Estados Unidos pueden prever una defensa del petróleo mexicano contra la inestabilidad interna o la amenaza soviético-cubana. A la inversa, los políticos demócratas y republicanos tienen opiniones e intenciones divididas respecto a la creciente población hispana del suroeste de los Estados Unidos, que constituye una creciente fuerza electoral con lazos culturales, lingürsticos y reales con México y, cada vez más, con América Central. Este bloque de electores en desarrollo podría llegar a tener un papel significativo en la polf́tica externa así como una posibilidad no necesariamente utilizada por la banca norteamericana 4 .

Si la legislación de inmigración respecto a los mexicanos del Suroeste representa el lazo de unión entre asuntos nacionales y relaciones MéxicoE.U.A., el área de la frontera de México constituye la región más directamente impactada por esta legislación.

Entender las presentes condiciones económicas en México y su frontera con Estados Unidos, revela mucho acerca de las causas y efectos del nuevo proyecto de ley sobre inmigración. Para poder acercarnos más a la perspectiva de los Estados Unidos respecto a sus relaciones con México, debemos primero explorar la naturaleza de la relación económica entre estos dos países.

\section{MEXICO: UNA ECONOMIA REACTIVA.}

En años recientes, las economías de la mayoría de los países del tercer mundo se han vuelto cada vez menos capaces de un crecimiento autosuficiente. En agricultura, una marcada declinación en la producción de básicos para el consumo interno ha llevado a una confianza mayor en las importaciones extranjeras de productos alimenticios. El nuevo desarrollo ha sido enca-

"Ver, Charles Mathias, Jr. "Ethnic groups and foreign policy", en Foreign Affairs. Vol, 59, No. 5., verano de 1981. 
minado principalmente hacia la producción agrícola mecanizada de algún cultivo en especial o hacia la producción de artículos de lujo con mercado limitado, ambos utilizados generalmente para la exportación.

En los sectores industriales, a pesar del incremento de la producción total en áreas particulares, hay poco crecimiento en los sectores claves productores de bienes básicos. Las empresas manufactureras se han concentrado principalmente en la producción de bienes de consumo para uso interno o en operaciones del tipo de ensamble, designadas para la exportación. Por lo tanto, existe poca integración entre los sectores industrial y agrícola de la mayoría de los países del Tercer Mundo. La productividad o la inversión en agricultura no se derivan principalmente de cambios en las necesidades o cambios internos, sino más bien de cambios en el mercado mundial, especialmente aquellos de las naciones industriales avanzadas. En consecuencia, la producción de granos y productos alimenticios en los países industriales avanzados abastece, de manera insu ficiente, la demanda de la creciente población urbana del Tercer Mundo.

Similarmente, el crecimiento del sector industrial depende no de la producción de bienes de capital que pueden servir para abastecer los requerimientos de la creciente base agrícola, sino principalmente de las opciones de las corporaciones extranjeras para ubicar en los países del Tercer Mundo, algunas de sus operaciones que requieren un uso intensivo de mano de obra.

De este modo, las economías de aquellas naciones se están volviendo de carácter reactivo. Reaccionan a toda clase de causas externas: inflación en los Estados Unidos, devaluaciones del dólar, desarrollo biotecnológico, etc. Su desarrollo agrícola e industrial tiene lugar en sincronía con (o como un apéndice de) los cambios económicos internos de los países industriales avanzados.

Esta "división internacional del trabajo", lejos de beneficiar a los países del Tercer Mundo, ha ampliado la distancia entre las naciones ricas y las pobres. La ausencia de una soberanía económica real ha resultado en el empobrecimiento generalizado y en la destrucción de las esperanzas de futuras mejoras en el nivel de vida de los habitantes del Tercer Mundo.

México, un país que exporta el $60 \%$ de su producción total a los Estados Unidos y que toma un $70 \%$ de importaciones de su vecino del Norte, es un caso digno de tomarse en cuenta. Entre 1970 y 1980 la población de México creció de aproximadamente 50 millones, a más de 70 millones de personas. En el mismo espacio de tiempo, la producción de maíz, frijol y trigo, los tres artículos básicos en la dieta diaria de sus habitantes, sufrió una importante baja. La producción de trigo, por ejemplo, bajó de 2 mil 
700 millones de toneladas en 1970 , a 2 mil 300 en 1979. La producción de frijol bajó de 900000 toneladas en 1970, a 500000 en 19795.

Algunos sectores de la economía agrícola mexicana se volvieron bastante productivos durante estos mismos años. Estos sectores están mecanizados y muestran altos índices de crecimiento. También han sido áreas de inversión masiva por parte de las multinacionales de Estados Unidos, las que han hecho que ciertas partes del campo mexicano se vuelvan zonas de producción en gran escala. Pero la mayoría de esa producción, usualmente vegetales, forrajes, etc., ha sido impulsada no para satisfacer las necesidades alimentarias de la población mexicana, sino para expandir el mercado de exportaciones de modo directo o indirecto. Actualmente, los vegetales frescos y el ganado exportado a los Estados Unidos comprenden un importante sector de las exportaciones totales de México 6.

En suma, en los últimos quince años el sector agrícola mexicano ha sido transformado y organizado para producir artículos de exportación, principalmente hacia los Estados Unidos de América. Al mismo tiempo, la tierra y los recursos dedicados a producir los alimentos básicos de la población mexicana han disminuido.

\section{EL PAPEL DE LOS ESTADOS UNIDOS.}

La influencia de las corporaciones multinaciones de Estados Unidos en los cambios del sector agrícola de México entre 1970 y 1980 , tuvo un paralelo en el sector manufacturero. Mucho del crecimiento de la producción manufacturera en la economía mexicana se debió a inversiones muy fuertes por parte de las firmas de los Estados Unidos desde 1945.

En 1940 la inversión extranjera directa en el ramo de industrias manufactureras en México representó sólo el 7 \% del total: en 1970 estuvo cerca del $75 \%$ y permaneció en esta cifra durante la década de los setentas.

Además de las importantes inversiones en agricultura e industria, otra forma de dominación más sútil, pero quizá más efectiva, fue desarrollada en la década de los setentas. La deuda externa, un método por el cual el gobierno de México ha utilizado fondos de instituciones de crédito internacionales, públicas y privadas, para financiar sus proyectos de desarrollo, se convirtió en el camino fundamental por el cual las empresas monopolistas mexicanas, estatales y privadas, fueron manipuladas y controladas por bancos internacionales.

${ }^{5}$ Ver, Jorge Calderón, Notas sobre la economía mexicana Mimeo. Facultad de Economía, UNAM, México D.F, 1981 .

6David Barkin, "Tres crisis alimentarias". Estudios Frontenizos. Año 1, No. 2, 1983. 
Sólo en 1979 México tuvo que pagar 3,000 millones de dólares en intereses más 7,000 millones en amortización para sus acreedores externos, México tuvo que pedir prestados aproximadamente 7,000 millones de dólares a fin de ser capaz de pagar la deuda que habra que saldar en ese año. En 1980 la deuda externa oficial era arriba de los 32,000 millones de dólares. Hacia 1984 , después de una gran "fianza" otorgada por los bancos de Estados Unidos, la deuda habra subido a 80,000 millones de dólares con pagos anuales de 10,000 millones 7. El tamaño de la deuda mexicana contraída con los bancos estadounidenses ha hecho al sistema financiero de E.U.A. muy suspicaz ante la capacidad de México para pagar sus deudas.

En 1984 sólo dos bancos principales de Estados Unidos, Continental de Illinois y Manufacturers Hanover, principales acreedores de México, enfrentaron cifras de pánico. A corto plazo, la capacidad de México para manejar la carga de la deuda externa podría verse influenciada por el tamaño del déficit en el presupuesto federal de los E.U.A.

A través de las dos décadas pasadas, el gobierno de Estados Unidos habfa confiado en una economía con défícit financiado, pero la magnitud del déficit alcanzó proporciones sin precedente durante el primer período de Ronald Reagan. En 1983 el gasto del gobierno alcanzó 795,000 millones de dólares con intereses de 600,000 millones, Ios cuales lo llevaron a un déficit de cerca de 200 mil millones de dólares.

Este aumento es una consecuencia directa del programa económico de Reagan: incremento masivo en el presupuesto militar, diseñado para reforzar la maquinaria militar americana contra la amenaza soviética, combinado con amplias reducciones de impuestos para corporaciones financieras e industriales. El presupuesto militar creció 3 \% más rápido que los gastos totales del gobierno en 1983, hasta un total de 205 mil millones, o la cuarta parte del presupuesto total de los Estados Unidos.

Simultáneamente a lo anterior, los ingresos del gobierno bajaron en 22 mil millones debido a las medidas de reducción de impuestos. Para cubrir este amplio déficit, la Tesorería de E.U.A. se ha convertido en un poderoso competidor en lo referente a fondos para préstamos tanto en el mercado nacional como en el internacional, causando presión hacia el alza en las tasas de interés. Dado el incremento de la demanda de préstamos generado por la actual recuperación económica en los Estados Unidos y la política constante de estricto control de suministro monetario, ejercido por el Banco de Reserva Federal de E.U.A., la tendencia hacia el alza en las tasas de interés probablemente continuará sin disminución a corto plazo.

\footnotetext{
7 Una idea del tanıaño del déficit mexicano en lo referente a importaciones agrfcolas, está dada por la siguiente cmiparación: el valor de las importaciones de alimentos de 1979 totalizó casi tres cuartas partes del valor total de las exportaciones de petróleo mexicano en ese mismo año.
} 
Puesto que los préstamos para México están vinculados en varias formas a las tasas de préstamos de los bancos estadounidenses, el resultado sería un incremento concomitante en los pagos anuales de México o en su deuda. Los ingresos adquiridos por el auge repentino de las exportaciones de petróleo mexicano están siendo usadas en gran medida para costear intereses y amortización en la deuda, así como para cubrir déficits causados por la gran crisis agrícola. A pesar de los enormes ingresos provenientes de la venta de petróleo, México tiene un déficit comercial y está teniendo que incrementar la producción de petróleo y exportar más para poder hacer frente a la creciente deuda y a una agricultura que empeora cada día.

Las inversiones extranjeras directas en México estaban estimadas en aproximadamente 6 mil millones en 1980. Esta inversión está concentrada en los sectores más dinámicos de la economía, pero el provecho de la inversión es minúsculo si se compara con la cantidad de dinero que sale de México para hacer los pagos de su deuda.

La actual política económica mexicana puede ser resumida como un círculo vicioso: aumentar la producción de petróleo para hacer frente a una crisis de su deuda debido a la creciente importación de alimentos; subsecuente aumento en la deuda externa a fin de desarrollar la industria petrolera, mayores aumentos en las exportaciones de petróleo para afrontar la deuda externa.

Las recientes devaluaciones de 1982 y 1983 , planeadas para mejorar la balanza comercial, dieron como resultado una tremenda baja en la importación de materia prima, equipo y maquinaria indispensable para la producción local de algunos bienes manufacturados. Esto condujo a un bajo rendimiento en todos los sectores de la industria en 1983 8. En esta circunstancia, algunos legisladores de Estados Unidos están, lógicamente, al pendiente de los posibles efectos negativos que la propuesta de reforma a las leyes de inmigración puede tener en la economía mexicana en su conjunto.

\section{LA ECONOMIA FRONTERIZA.}

El patrón de inversiones de E.U.A. en México ha producido una economía dislocada. En 1975, más del $70 \%$ o de toda la producción industrial del país fue concentrada en el Distrito Federal de la ciudad de México y en el adyacente estado de México; en parte del área metropolitana de la ciudad de México; en la cercana ciudad de Puebla; en Monterrey, Nuevo León, y en Guadalajara, Jal. Más del $50 \%$ de la producción manufacturera total está localizada solamente en el área metropolitana de la ciudad de México.

${ }^{8}$ New York Times, enero 15, 1984. 
La expansión de la agricultura mecanizada que pretende cultivos renta. bles para exportación, ha generado una inmensa migración de las regiones rurales a las urbanas. Este flujo de población no ha encontrado una rápida fuente de empleo en los centros urbanos, dado el carácter monopolista de la industria manufacturera en las ciudades, lo cual influye en la migración de población rural mexicana hacia el suroeste de los Estados Unidos.

El carácter reactivo de la economía mexicana halla su punto álgido en la frontera norte de México, región carente de homogeneidad. Geográfica mente está dividida en tres regiones principales: la región noroeste, que comprende a Baja California y parte de Sonora; la región central, que cubre parte de Sonora y Chihuahua, y la parte noreste, que abarca varias ciudades en los estados de Coahuila, Nuevo León y Tamaulipas.

Dentro de cada región existe una red de comunicaciones que provee cierto grado de integración. Por ejemplo - en la región noroeste-, Ensenada, Tijuana, Mexicali, San Luis Río Colorado y Sonoyta están conectados por carretera. En el Noreste, las ciudades de Nuevo Laredo, Reynosa y Matamoros están unidas también por carretera. Sin embargo, estos subsistemas de pocos municipios no tienen conexiones aunque estén todos conectados con distantes áreas urbanas centrales. Nogales, Ciudad Juárez y Piedras Negras son ejemplos de importantes centros urbanos sin lazos de comunicación entre ellas 9 .

La región fronteriza tiene poca integración con las actividades productivas de la región central de México y ninguna integración entre ellas mismas. El sine qua non de su desarrollo ha sido el grado y calidad de sus lazos con áreas al norte de la frontera, ya que el desarrollo en la economía de E.U.A. constituye el factor determinante en la tasa de crecimiento y en las diferentes estructuras económicas que caracterizan a esta zona.

En todos los países de América Latina la marcada corriente migratoria campo-ciudad ha resultado en amplias concentraciones urbanas en las ciudades capitales. En México, el área fronteriza se ha convertido también en un polo de crecimiento urbano debido a su adyacencia a los Estados Unidos.

\section{IMPACTO DEL DESARROLLO REGIONAL DE ESTADOS UNIDOS.}

La economra fronteriza mexicana está tan entrelazada con la economía de los Estados Unidos, que ha seguido el modelo del reciente desarrollo re:

\footnotetext{
${ }^{9}$ Jesús Tanayo y José Luis Fernández, Zonas fronterizas, CIDE. México, D.F, 1983.
} 
gional de ese país. California y Texas en el este y suroeste de los Estados Unidos respectivamente, son dos de los estados recientemente desarrollados que desde la II Guerra Mundial han ejercido influencias sobre el área de la frontera mexicana en importantes y distintas formas. Las seis ciudades principales de la frontera mexicana están ligadas a la economía de estos dos estados: Mexicali y Tijuana en la frontera de California; Ciudad Juárez, Laredo, Reynosa y Matamoros en la frontera de Texas.

El crecimiento económico de California desde el final de la Il Guerra Mundial hasta los años setenta, implica el desarrollo de una enorme agricultura intensiva de capital, la construcción de proyectos masivos de irrigación, el desarrollo (en el área de Los Angeles) de una pesada industria manufacturera, y la aparición de modernas empresas procesadores de alimentos y empresas manufactureras.

Entre 1938 y 1959 el empleo agrícola en los estados del lejano Oeste (California, Nevada, Arizona y Washington), creció a más del doble como una consecuencia del crecimiento en el sector agrícola. Durante el mismo período, el empleo agrícola nacional bajó de 27 al 12.9 \% o. Esto hizo al lejano Oeste, y particularmente a California, un imán para la corriente migratoria: Este a Oeste en los Estados Unidos, Sur a Norte en México. La agricultura en California ofrecía dos características adicionales: su especialización en hortalizas y frutas cítricas, las cuales requieren una mayor cantidad de mano de obra 10.

El gran desarrollo industrial de Los Angeles y San Diego hasta 1970 no se convirtió en una fuente de empleo para trabajadores mexicanos a causa de la calificación requerida. Sin embargo, a finales de los sesentas las corporaciones industriales comenzaron a tomar ventaja de la proximidad de la frontera para dividir el sector manufacturero en dos ramas: la primera, caracterizada por relativamente más operaciones de capital intensivo centradas en Los Angeles; la segunda, notoria por su uso de métodos intensivos de trabajo, se convirtió en lo que es conocido como Programa Industrial de la Frontera (ver adelante.

Los cambios económicos en Texas difieren sustancialmente de los de California, a partir de la II Guerra Mundial y en adelante. La cría de ganado fue reemplazada por agricultura extensiva: algodón, frijol soya, trigo y maíz. La extracción de petróleo y gas, y la industria petroquímica crecieron al mismo tiempo que la propagación del automóvil y el desarrollo de una economf́a nacional basada en el uso masivo de los derivados del petróleo.

10 olga Ester Torres Ramírez, La economia de frontera. El caso de la fromtera norte de México. México. D.F., 1979 . 
Las características específicas de la economf́a texana han llevado a una configuración urbana de menos densidad que California, con la población concentrada lejos de la frontera mexicana, ya sea en la sección norte del estado (cerca de las principales áreas productoras de petróleo), o en la costa del Golfo, donde el crecimiento industrial ha tenido lugar. De este modo, con excepción del área de Ciudad Juárez-El Paso, el crecimiento de los pueblos fronterizos no ha sido tan espectacular como en la frontera de California11.

\section{EL PROGRAMA INDUSTRIAL DE LA FRONTERA}

En la última década, los centros urbanos de la frontera norte de México han sufrido cambios graduales. El fin de la década de la guerra de Vietnam y la consecuente disminución del personal militar situado cerca de la frontera ocasionaron una reducción del turismo militar. Un relativo incremento en el turismo familiar tuvo lugar; servicios ilegales como la prostitución declinaron para ser reemplazados por otros servicios profesionales como dentistas, salones de belleza y barberías.

EI cambio adquirió mayor fuerza con la creación del Programa Industrial de la Frontera (BIP)12. Bajo el BIP, a las compañáas de los Estados Unidos les es permitido introducir a México, libres de cargas fiscales, componentes que requieren ensamblado o toques finales. Bajo estipulaciones especificas del Código Fiscal de E.U.A., la mercancía terminada es importada de nuevo a los Estados Unidos, con un impuesto gravable sólo en el valor agregado en México. Esta cantidad es mínima debido a los bajos salarios prevalecientes en México, que son el $100 \%$ del valor agregado.

Las alabanzas oficiales con respecto a las promesas del BIP en términos de empleo, generación de ingresos y avance tecnológico para México, han sido refutadas desde tiempo atrás por varios autores 13 . Sin embargo, después de 15 años de continua operación, el ensamble manufacturero es un factor prevaleciente en la vida de las ciudades fronterizas. Un estudio de Suárez ${ }^{14}$ confirma en detalle una temprana especulación de otros autores respecto a que el área fronteriza se ha convertido en el lugar donde se realizan las últimas fases de varias manufacturas estadounidenses.

\footnotetext{
11 Mientras que las ciudades fronterizas de California están más directamente dedicadas a desarrollar ciertas funcionés específicas para la economía californiana, el complejo Juárez-El Paso es más bien una unidad económica autocontenida, con menos vinculos ya sea con la economía de Texas o con la de México. $\mathrm{L}_{a}$ disponibilidad de mano de obra batata en esta zona urbana, ha dado origen a una industria textil. Por otro lado, la agricultura texana ha tomado ventaja de la mano de obra barata proporcionada por México, pero no al grado que en California.

12 Raúl Fernández, La frontera Méxica-Estados Unidos. Editorial Terra Nova, México, D, F. 1980.

13 Fernándex, op, cit.

14Luis Suárez Villa, "The manufacturing process cyde and the industrialization of the United States-Mexico borderlands", The Annals of Regional Science, vol. XVII, no. 1, marzo 1984.
} 
En otras palabras, antes que la producción de mercancías particulares llegue a un alto o que el cambio hacia una nueva tecnología tenga lugar, los fabricantes de Estados Unidos utilizan el mecanismo del BIP para reubicar sus industrias y continuar su producción a un nivel muy redituable.

El BIP provee el último asidero para industrias decadentes de Estados Unidos, las cuales representan la mayoria de las que utilizan este programa.

Los ciclos del BIP, como la migración, parecen más directamente conectados con las altas y bajas de la economía mexicana en conjunto15. La industria en el norte de México y las expectativas de empleo que genera, han llegado a vincularse estructuralmente con la industria de E.U.A. Un limitado programa que busca tomar ventaja de una vasta oferta de mano de obra barata se ha convertido, 16 años después, en un rasgo permanente de la base económica de estas áreas urbanas, lo cual aumenta el atractivo de "emigrar hacia el Norte".

La reciente decisión de la Ford Motor Company en el sentido de inverir 500 millones en una planta en Hermosillo, para la producción de automóviles de bajo costo para exportar a los Estados Unidos, muestra que la tendencia establecida por el BIP habrá de continuar16.

Los lazos entre la economra mexicana y la de Estados Unidos evidentemente han producido una profunda transformación en la mayor parte de la región norte de México. Los recientes esfuerzos por controlar la migración de indocumentados deben ser examinados ante este trasfondo.

\section{LA SITUACION ACTUAL DE LA INMIGRACION.}

La reciente preocupación en los Estados Unidos acerca del volumen de la migración de indocumentados ha sido usada en provecho de intereses políticos que buscan en esta gente un chivo expiatorio de la crisis económica de los Estados Unidos.

Desde el último año de la administración de Carter, los polfticos republicanos y demócratas han buscado reformas sustanciales en las leyes de inmigración de los E.U.A. para poder enfrentar la migración masiva de indocumentados.

En 1965 se hizo un gran cambio de política en el Acta de Inmigración y Naturalización de los Estados Unidos, poniendo cuotas para la inmigración

$15 \mathrm{~J}$. Manuel Luna Calderón, México, crecimiento orientado por exportaciones y segmentación de proceso productivo. La industria maquiladora. 1966-1982. CIDE. México, D,F, 1983.

16 Business Week, enero 23, 1984, pp. 43-44. 
proveniente del hemisferio occidental. El efecto práctico de esta ley fue obstruir la inmigración legal de latinoamericanos y transformarlos en indocumentados o los llamados inmigrantes "ilegales".

El tamaño de la migración ha sido fenomenal. Los Angeles se ha convertido en el segundo centro mexicano metropolitano después de la ciudad de México; Nueva York es ahora la ciudad con mayor cantidad de puertorriqueños. Colombia, con una población de 27 millones, tiene arriba de medio millón de personas en los Estados Unidos.

En la década de los setentas este flujo de migración se vio aumentado por un período de declinación económica global. La crisis en empleo y producción ha afectado a Latinoamérica muy profundamente, dando un $1 \mathrm{~m}$ petu adicional a la migración hacia Estados Unidos.

En años recientes, cambios en las tasas de crecimiento y en el patrón de empleo en Los Angeles y en el área del sur de California convirtieron la presencia de trabajadores indocumentados en un problema político nacional. Cierres en la industria básica, ocurridos en el Noreste, Medio Oeste, Noroeste y el Sur, se extendieron al Suroeste. California, que ha atraído trabajadores de todos los Estados Unidos desde la época de posguerra debido a su diversidad de industrias y a su clima favorable, fue clasificada en segundo lugar en la lista de estados más afectados (en términos de empleo) por los cierres de fábricas a principios de los ochenta (ver cuadro 1). Los Angeles, el anfitrión de los juegos olímpicos de 1984 y una ciudad con una reputación mundial por su estilo de vida, entretenimiento y tendencia modernista, no se quedó atrás.

Durante los cincuentas, el de Los Angeles fue el sector manufacturero que creció más rápidamente en la nación. Al cierre de la década el condado de Los Angeles tenfa una población de seis millones, la cual representaba 1.9 millones más que en los cuarentas. Hasta mediados de los setentas Los Angeles fue un área industrial próspera, rodeada por unas pocas comunidades habitacionales, el hogar de los trabajadores blancos e hispanos.

Al iniciar el fin de los sesentas y durante los setentas,el patrón de crecimiento de empleo en manufacturas básicas comenzó a cambiar. Hacia 1980, por ejemplo, hubo una significativa baja de empleo en la industria automotriz. Las plantas industriales de caucho comenzaron a cerrar.

Dos estudios recientes 17 indican que esa tendencia continuará en el futuro previsible. El rápido crecimiento de la industria es una cosa del pasa-

17 Kevin F. McCarthy, The slow-growing orange. A demographic's look at future Los Angeles, The Rand Paper Series, April 1984; Thomas Muller, The fourth wave, The Urban Institute Press, 1984. 
do, Los cambios de población serán lentos para el resto de este siglo; la habilidad de la región para atraer y absorber la migración de mano de obra está desapareciendo.

Este cambio en el patrón del crecimiento regional de los Estados Unidos incrementó la visibilidad polf́tica sobre los trabajadores indocumentados y dio impetu a los que proponían reformas de inmigración.

Lomo veremos adelante, las reformas a la inmigración vendrán a agudizar el impacto que, sobre la economía fronteriza mexicana, tuvo el cierre de fábricas en el sur de California.

CUADRO I. Plantas clausuradas por el Estado. 1982.

\begin{tabular}{|lcc|}
\hline Estado & Fábricas cerradas & Trabajadores afectados \\
\hline Carolina & 61 & 7,609 \\
Ohio & 58 & 18,006 \\
Pennsylvania & 45 & 15,679 \\
California & 32 & 16,789 \\
New York & 29 & 5,381 \\
Illinois & 28 & 8,701 \\
Michigan & 25 & 6,877 \\
Indiana & 21 & 11,231 \\
Massachusetts & 21 & 8,654 \\
West Virginia & 16 & 5,264 \\
\hline
\end{tabular}

Fuente: Economic Notes, junio de 1983.

\section{LAS PROPUESTAS DE REFORMAS A LA INMIGRACION.}

Las varias secciones de la propuesta de reformas a la inmigración se unen alrededor de un problema político central: puesto que ya no existe un camino efectivo para detener directamente o siquiera controlar, el flujo de migrantes de México, ces factible hacerlo por medio de la regulación de la condición de los mismos trabajadores indocumentados?

¿Es posible negar a los trabajadores indocumentados los pocos derechos que tienen mientras se encuentran en los Estados Unidos y procurar mejorar la habilidad del Gobierno para deportar a muchos de ellos a través de esa medida?

Comúnmente, los trabajadores indocumentados viven bajo el constante temor de la deportación, pero este método de control se ha vuelto cada vez menos aplicable y efectivo. El tamaño de la población en cuestión es muy 
grande; el número de oficiales del Servicio de Inmigración y Naturalización (INS) es pequeño; la longitud de la frontera es tal, que se convierte en algo difícil para la Patrulla Fronteriza vigilar esa zona en un grado significativo.

Las redadas de los oficiales del INS producen pocos resultados en la reducción de la población indocumentada, pero sí producen mucho en hostigamiento humano, vejación comunitaria y abuso personal de individuos trabajadores. Políticamente, la deportación se ha vuelto un instrumento tan impopular como infectivo para frenar la migración de indocumentados.

Por otra parte, ser un extranjero "ilegal" actualmente no priva al trabajador o a su familia de todos los derechos y beneficios disponibles para los trabajadores de E.U.A. Por ejemplo, el Acta Nacional de Relaciones Laborales protege los derechos de los trabajadores de organizarse o lanzarse a la huelga sin hacer referencia a su situación ciudadana. Esta inconsistencia entre las leyes de inmigración y las de trabajo, aunque no probadas en las cortes e ignoradas por las uniones afiliadas a AFL-CIO, ha sido utilizada por Ia Unión Internacional de Trabajadores de Prendas Femeninas (International Ladies Garment Workers Union) en Los Angeles, y por la Unión de Trabajadores de Ranchos de Texas (Texas Farm Workers Union). 18

Un segundo ejemplo es dado por una reciente decisión de la Corte $\mathrm{Fe}$ deral del Distrito de Estados Unidos, la cual reconoce a los niños indocumentados el derecho a la educación sin hacer caso de la condición migratoria de los padres o de los propios niños. Esta decisión, basada ampliamente en una interpretación del alcance de la estipulación de protección igualitaria de la Decimocuarta Enmienda, puede significar extensas implicaciones para las personas indocumentadas, más allá del campo de la educación; por ejemplo, en términos de salud, cuidado, programas habitacionales, estampillas para alimentos, etc. 19

Estos desarrollos judiciales han tendido a desgastar la relación de completa subordinación de estas personas para darles acceso a las ventajas de vivir en los Estados Unidos.

Cuando se examinan cuidadosamente las nuevas reformas a la inmigración, se manifiesta un impulso destinado a debilitar los derechos democráticos de los indocumentados: un impulso que consiste en la aparente suspensión de la amenaza de deportación que, elaborada con cuidadosas palabras es esencialmente confusa y desorientadora; es decir, la propuesta de "amnistía".

18 Comunicación con Rosalinda Gonzâlez.

${ }_{19}$ Consejo Nacional de la Raza (National Council of la Raza), Issue andysis of the seals decision, febrero 3,1981. 
Bajo la sección de "amnistía", los "extranjeros" que han vivido en los Estados Unidos antes de una fecha estipulada, podrán quedarse por un término específico hasta de 10 años. Durante estos períodos de "contrato" con el Gobierno de Estados Unidos, las personas pagarán impuestos, pero oo podrán llevar a sus familias, ni recibir la asistencia federal de la vivienda, seguro de desempleo, o estampillas para comida. Esta sería su situación bajo la supervisión del Gobierno, después de haberse entregado ellos mismos, 2 reserva de ser aprobados por las autoridades como admisibles para la amnistía. Entonces, mientras que comúnmente los trabajadores indocumentados tienen la posibilidad de unirse a un gremio obrero, tener educación para sus hijos y escapar de la detención, la propuesta de amnistía eliminaría dichas ventajas y pondría a estos trabajadores en una limitada situación de "prueba" que ha estado ligada al pretendido programa de extranjeros.

El debate sobre cuál programa de "amnistía" es más liberal, si el que extiende la condición de residencia continua necesaria para calificar sin documentos hasta 1981, o el que lo hace a 1980 o 1977 , olvida el punto sobre la verdadera naturaleza de la amnistía; la velada restricción de cualquiera de los derechos que los trabajadores indocumentados tienen actualmente.

Es ridículo esperar que un amplio número de gente que ha hecho grandes esfuerzos para no dejar huella de su presencia en los Estados Unidos, ahora se descubra voluntariamente sólo para ser deportado por falta de "calificación" o para entrar en un programa con condiciones de trabajo más onerosas y sin garantías sobre su residencia permanente. Con todo, la legislación espera ejercer presión para llegar a este objetivo por medio de la sección de "sanciones a patrones" contenida en el proyecto de ley.

El abogado general de Reagan, William French Smith, ha arguido abiertamente que la "piedra angular" del programa es una propuesta de ley prohibiendo a los patrones emplear a extranjeros ilegales 20 . Bajo esta estipulación de ley, el patrón que emplee cuatro o pás trabajadores indocumentados será multado con 500 a 1,000 dólares por cada trabajador empleado.

Las repercusiones de esta estipulacion han sido abundantemente criticadas en varios foros. Los patrones quizá dejen escapar algunos empleados por miedo a que por "parecer mexicanos", sean considerados ilegales y a que ellos tuvieran que enfrentar las multas. La estipulación podría también ser utilizada como un escudo por Ios patrones si ellos despidieran del trabajo a activistas y simpatizantes de las uniones, alegando su ausencia de documentos.

${ }^{20} \mathrm{Ver}$, Immigration reform and Control Act of 1982, audiencias conjuntas ante el Subcomitt de Inmigracion, Refugiados y de Ley Intemacional del Comité del Poder Judicial, Cámara de Representantes y Subcomité sobre Inmigración y Polrtica de Refugiados del Comité del Poder Judicial, Senado de los Estados Unidos, XIX Congreso, abril 1 y 20, 1982, Washington, GPO, 1982. 
Así, los trabajadores indocumentados están atrapados en el "fuego cruzado" de la legislación. Los trabajadores quizá enfrenten la discriminación y el desempleo a causa de la estipulación de sanciones a patrones, o tal vez lleguen a entregarse a las autoridades del INS. En este último caso pueden ser deportados si no califican; y si lo hacen, habrán de encarar las desventajosas condiciones de trabajo, y aun la deportación si al final del período convenido son considerados no calificados pra la admisión bajo las bases normales.

Deportar a algunas personas y controlar a otras más estrechamente, son las dos metas de estos dos aspectos de la legislación. Las personas deportadas a México posiblemente podrían volver a E.U.A. por medio de una tercera legislación; el Programa de Trabajadores Huéspedes. Bajo esta propuesta, 100,000 trabajadores (50,000 anualmente en un período de dos años) serían traídos de México a trabajar principalmente en agricultura a gran escala en los estados del Suroeste.

Quienes hacen esta propuesta preven el programa creciendo a mayores proporciones. Se le exigiría al patrón pagar impuestos de Seguro Social y contribuciones para el seguro de desempleo, pero a los trabajadores no se les permitirfa traer a sus esposas e hijas, se les serfa negado el acceso a la labor social o de beneficiencia, a las estampillas para alimentos, y no serían candidatos para la compensación de desempleo.

El Programa de Trabajadores Huéspedes hace recordar el Programa de Braceros de 1950; puede fácilmente ser usado por los agricultores para evadir el cumplimiento de contratos firmados con la United Farm Workers Union (UFW).

Dado el incremento de los lazos entre los E.U.A. y México, y el desarrollo del área fronteriza con su amplia y creciente población como complemento de la economía de los Estados Unidos, el Gobierno de este país ha optado por impulsar un plan de reformas de inmigración designadas para beneficiar a los patrones poniendo a la gran masa de trabajadores indocumentados bajo restrictivas condiciones de trabajo.

\section{PERSPECTIVAS DE LA ECONOMIA EN LA FRONTERA}

Hemos visto cómo el rápido crecimiento de la economía de la frontera de México en los últimos 20 años, desde el cierre del Programa de Braceros a principios de los sesentas, ha sido guiado por fuerzas externas provenientes de Estados Unidos. 
Ante la migración masiva de trabajadores mexicanos indocumentados hacia las fábricas de la cada vez mejor economía del sur de California, en un principio el Gobierno de los Estados Unidos decidió prestar poca atención al cumplimiento de las leyes de migración establecidas. El oleaje de migración hacia el Norte se extendió más alla de México hasta Centro y Sudamérica, lo cual contribuyó para saturar los centros urbanos del norte de México que, durante dos décadas, experimentaron altas tasas de crecimiento de población.

El desarrollo de una compleja área industrial en Los Angeles y sus alrededores, muy cerca de la frontera mexicana, dio lugar a la formación de una subsección caracterizada por métodos de uso intensivo de mano de obra al sur de la frontera (BIP).

El programa industrial de ensamble también creció para convertirse en un componente inseparable de la economía de la fronterza, así como en un factor de atracción adicional en lo referente al empleo de migrantes provenientes del resto de la República Mexicana.

La economía del sur de California experimentó disminución y contracción en los últimos años. Ya no es la región con crecimiento espiral en términos de desarrollo económico; ya no puede ofrecer una aparentemente interminable fuente de oportunidades de empleo como lo hizo a principios de los sesentas; así, la declinación del empleo industrial en esta sección del país, su intensa atracción para trabajadores indocumentados, pudo disminuir en cierta medida.

La baja en la migración hacía el sur de California y/o la propuesta de reforma a la inmigración, si se decreta, pueden traer cambios en la calidad y dirección de la expansión demográfica en la región fronteriza en conjunto, lo cual puede ser cierto debido a varios argumentos importantes.

Primero. Dada la naturaleza del uso intensivo de mano de obra por parte de la industria de ensamble, el declive de la economía en el sur de California, puede no resultar en una baja paulatina de las actividades del BIP en las ciudades fronterizas del noroeste de México. La industria ensambladora puede verse estimulada por la serie de devaluaciones de la moneda mexicana en conexión con los esfuerzos de México para mejorar su balanza comercial.

Segundo. La intención de la propuesta de reforma a las leyes de inmigración es, en parte, para repatriar al menos una parte de trabajadores indocumentados. Por lo tanto, el impacto que tengan los primeros períodos de expulsión sobre las ciudades de la frontera de México, puede ser útil en la exploración de las implicaciones de la legislación Simpson-Mazzoli. Por 
ejemplo, el cierre del Programa de Braceros en 1964, exacerbó la situación de desempleo en las ciudades fronterizas porque muchos braceros que ya no pudieron trabajar en los Estados Unidos decidieron permanecer en el norte de México en vez de retornar a sus lugares de origen.

La creación del Programa Industrial de la Frontera por el presidente Díaz Ordaz, en 1965, estaba justificada en parte como una forma de aliviar el desempleo general prevaleciente a lo largo de la frontera. Un aumento del número de indocumentados que se establezcan en las ciudades fronterizas puede muy bien constituir el paso siguiente a la reforma de la legislación estadounidense en materia de inmigración.

Tercero. Este cambio en la calidad de la población residente en las ciudades fronterizas puede, a su tiempo, llegar a dar prominencia a un tipo de migración apenas mencionada en los varios debates con respecto a la legislación Simpson-Mazzoli: la migración de los llamados commuters , personas que viven en las ciudades fronterizas y diariamente cruzan la frontera para trabajar en los Estados Unidos bajo una estipulación especial del INS2 1.

En E.U.A., la migración de los commuters constituye una parte importante de la fuerza laboral en las áreas adyacentes a la frontera con México. Por ejemplo, en 1967 representaban el 28\%/o de la fuerza de trabajo empleada en el condado de Imperial (California) 22.

A finales de los sesentas, después del cierre del Programa de Braceros, el impacto de la discusión entre la opción commuters o la de empleo y salarios en las áreas fronterizas de Estados Unidos, ocupó la atención central en debates locales y del Congreso con respecto a la política de inmigración de los Estados Unidos.

Si una legislación como la Simpson-Mazzoli es promulgada, debemos esperar, junto con la reubicación en las ciudades fronterizas de los anteriormente trabajadores indocumentados, un incremento en el número de personas que, a la vez que viven en México, tratarán de obtener empleo diario en los Estados Unidos. $\mathrm{Y}$ en tanto que en los actuales debates en los E.U.A. parece ignorarse el fenómeno de los commuters, una vez que la reforma a la legislación sea decretada, este tipo de migración, emanada directamente de las ciudades fronterizas, puede convertirse en el foco de contención sobre la migración mexicana a los Estados Unidos.

\footnotetext{
${ }^{21}$ Citado en Guadalajara Beatriz Acuña, "Migración y fuerza de trabajo en la frontera norte de México", Estudios Fronterizos, año 1, no. 2, 1983.

22 Esta posibilidad hace que la investigación en este tipo de migración sea aún más relevante. Es importante reunir datos acerca de todos los aspectos del tenómeno de commuting a fin de ser capaces de evaluar apropiadamente el campo y la significancia de sus cambios futuros.
} 
Cuarto y último. Debemos esperar que las condiciones generales de las relaciones económicas E.U.A.-México impacten el desarrollo industrial del área fronteriza en un modo nuevo y diferente; esto es, en la forma de inversiones directas más allá del mero proceso de ensamble.

En la cumbre económica de Londres, en junio de 1984, los líderes de las naciones de Occidente, guiados por el presidente de Estados Unidos, Ronald Reagan, hicieron un llamado a los países deudores, como México, para que concedieran la entrada a inversiones extranjeras como una salida para su crisis económíca. Varios países latinoamericanos (Colombia, Ecuador, Perú, Bolivia y Venezuela) ya han quitado buen número de restricciones legales al capital extanjero.

Si México permitirá una mayor y directa intervención de inversiones de capital estadounidense en su economía, depende de su habilidad para manejar los pagos futuros de la deuda externa. Como indicamos con anterioridad, esta habilidad será influida a corto plazo por otra política interna de Estados Unidos: el tamaño de su presupuesto federal.

Al final, México puede decidir volverse más abierto a las inversiones provenientes de Estados Unidos. Para las áreas fronterizas, el desarrollo de la planta Ford Motor en Hermosillo puede ser el presagio de las cosas por venir, significando el comienzo de una mayor integración de la región fronteriza a la economía de los Estados Unidos de América. 